\title{
QUESTÕES AMBIENTAIS URBANAS Articulação entre administrações locais e sociedade ${ }^{1}$
}

\author{
URBAN-ENVIRONMENTAL ISSUES \\ Articulation between local governments and society
}

\section{A. Clelia Maria Vieira Dantas \& B. Hugo Vigas Lima Dos Santos \& D. Miriam Medina-Velasco}

\author{
Bacharelado em Urbanismo - Universidade do Estado da Bahia, Brasil \\ cleliadantas@hotmail.com \\ hugo2.vigas@gmail.com \\ mmv.uneb@gmail.com
}

C. Anaie Leite Silva Morais

PPGEduc - Universidade do Estado da Bahia, Brasil

anaie.uneb@gmail.com

\section{RESUMO}

Brasil é signatário da Agenda 2030, portanto tem compromisso com a necessidade de tornar as cidades resilientes e sustentáveis. Este trabalho analisa a estruturação das capitais litorâneas do nordeste brasileiro para tratar das questões ambientais urbanas. O levantamento de dados realizado em sites de órgãos públicos possibilita construir análises numa perspectiva multirreferencial, histórica, institucionalista, sistêmica e pluralista sobre os instrumentos de governança ambiental, adotados nessas cidades, para garantir a articulação com a sociedade, considerando três tipos de variáveis. Os resultados revelam a heterogeneidade de órgãos gestores, instrumentos e processos nas oito capitais estudadas. Isto contribui para refletir sobre os desafios da articulação entre administrações locais e sociedade, na superação das desigualdades socioambientais, apontando-se preocupações sobre os modelos de governança fortalecidos no meio ambiente e nas políticas públicas, nas primeiras décadas do Século XXI.

Palavras-chave: questões ambientais urbanas, capitais litorâneas brasileiras, instrumentos de governança ambiental.

Linha de Investigação: Cidade e ambiente.

Tópico: Meio ambiente, paisagem e alterações climáticas.

\footnotetext{
1 Versão final: conteúdo melhorado integralmente atendendo às orientações dos avaliadores, preservando a essência da proposta aprovada.
} 


\section{SÃOPAULO15 17 LISBOA $25 \sim 26$ JUN 2020}

Seminário Internacional de

Seminario Internacional de Investigação em Urbanismo

\section{ABSTRACT}

Brazil is a signatory to the 2030 Agenda, therefore it is committed to the need to make cities resilient and sustainable. This paper analyzes the structure of coastal capitals around northeastern Brazil to address urban environmental issues. The data survey carried out on public agencies' websites, enables to build análisis from a multi referential, historical, institutional, systemical and pluralist perspective about the environmental governance instruments adopted in those cities to ensure their articulation with society considering three types of variables. Results reveal the management bodies, instruments and processes heterogeneity in the eight capitals that were studied. This contributes to reflect on the articulation challenges between local administrations and society in overcoming socio-environmental inequalities, pointing out concerns about the governance models strengthened in the environment and public policies, in the 21st Century's first decades.

Keywords: urban-environmental issues, coastal Brazilian cities, instruments of environmental governance. Research Line: City and environment.

Topic: Environment, landscape and climate change.

\section{Introdução}

Com a aprovação da Constituição de 1988, no Brasil fortaleceu-se a atuação do município na gestão da vida das cidades. Transcorridas mais de três décadas, interessa entender o cenário nas principais capitais litorâneas do Nordeste brasileiro, considerando as particularidades das questões socioambientais. Numa conjuntura, na qual a Agenda 2030 passa a pautar os objetivos e metas para melhorar as condições de vida, coloca-se como foco o Objetivo de Desenvolvimento Sustentável (ODS) 11 que busca "tornar as cidades e os assentamentos humanos inclusivos, seguros, resilientes e sustentáveis" como consta no documento do Instituto de Pesquisa Econômica Aplicada (IPEA, 2019).

Para contextualizar esta abordagem, cabe destacar, primeiramente, que a proteção do meio ambiente é consagrada, na Constituição brasileira de 1988, como uma competência comum da federação (união, estados, municípios), e estabelece que "todos têm direito ao meio ambiente ecologicamente equilibrado, bem de uso comum do povo e essencial à sadia qualidade de vida, impondo-se ao Poder Público e à coletividade o dever de defendê-lo e preservá-lo para as presentes e futuras gerações" (art. 225). Igualmente que, o Brasil é reconhecido pela estruturação antecipada de uma Política Nacional de Meio Ambiente (Lei 6938/1981) que institui os fins e objetivos dessa política, o sistema nacional e o Conselho de Meio Ambiente (CONAMA), para articular os instrumentos entre entidades da federação com representatividade da Sociedade. Assim, o conselho e outros instrumentos podem ser considerados como indicadores ou variáveis para atender o objetivo proposto.

A institucionalização do CONAMA revela-se nas diretrizes sobre meio ambiente como espaço de legitimação da governança ambiental, também no âmbito municipal e das cidades estudadas. Governança entendida como um modelo de interação entre poder público e sociedade na construção de uma agenda para o setor, garantindo espaços de diálogo, controle social e, especialmente, a participação na tomada de decisões (Leme, 2016). Nesse sentido, surgem preocupações com relação à articulação entre esferas de governo e sociedade, nas oito capitais litorâneas do Nordeste brasileiro, por sua liderança e visibilidade regional. Cabe ressaltar também que nelas repercute a Política Nacional para os Recursos do Mar (Dec. 5377/2005) que 


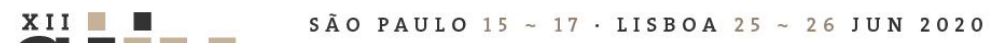 \\ Seminário Internacional de \\ Seminario Internacional de Investigação em Urbanismo

estabelece sua "execução descentralizada e participativa, incentivando as parcerias da União, dos Estados, dos Municípios, do setor privado e da sociedade".

Para entender como o poder público das cidades escolhidas se tem estruturado para tratar as questões ambientais no âmbito urbano e se aproximar com a sociedade, apresenta-se uma análise histórica e comparativa com base no levantamento e sistematização de algumas variáveis encontradas nos sites públicos, especialmente, na Pesquisa de Informações Básicas Municipais (MUNIC), divulgada pelo Instituto Brasileiro de Geografia e Estatística (IBGE) para os anos 2002, 2009 e 2017. Estes dados foram atualizados e complementados com a revisão de outros sites, particularmente do IPEA e das prefeituras das cidades deste estudo.

Como procedimentos para atender o objetivo, sistematizaram-se dados para três tipos ou grupos de variáveis: evolução do órgão gestor, caracterização do conselho municipal do setor e a definição de instrumentos normativos. Variáveis a partir das quais se pode analisar o processo de construção e os alcances da governança ambiental, no cenário 2002-2020 das cidades estudadas, tentando verificar, também, o modo como se incorpora uma das metas do ODS 11 da Agenda 2030 (IPEA, 2019), que explicita a necessidade de "aumentar a urbanização inclusiva e sustentável, aprimorar as capacidades para o planejamento, para o controle social e para a gestão participativa, integrada e sustentável dos assentamentos humanos, em todas as unidades da federação".

O trabalho está organizado em quatro partes, sendo que a primeira corresponde a esta introdução; a segunda, aborda os pressupostos teórico-metodológicos e a delimitação do estudo; a terceira, apresenta os dados e analisam as três variáveis propostas; por fim, na quarta parte, registram-se as considerações, ao modo de reflexões preliminares, que podem possibilitar a continuidade deste estudo.

\section{Delimitação sócio-espacial e perspectiva teórico-metodológica}

Para analisar, sob uma perspectiva histórica e de estudo de caso comparativo, o modo como as administrações locais têm se estruturado e se aproximado da sociedade para tratar as questões ambientais, tendo como referência o conjunto de cidades capitais litorâneas do Nordeste Brasileiro, , proposto aqui, prioriza as 8 (oito) capitais litorâneas, entendendo que a realidade sócio-ambiental e urbana destas cidades tem uma especificidade pela sua relação com os recursos e potencialidades marítimas, portanto, possibilitam comparações e análises mais equilibradas. Em ordem alfabética são: Aracaju, Fortaleza, João Pessoa, Maceió, Natal, Recife, Salvador e São Luís, ${ }^{2}$ e apresentam uma diversidade de tamanhos populacionais como se observa na figura.

\footnotetext{
${ }^{2}$ A região Nordeste tem 9 (nove) estados e fora das capitais selecionadas estaria a cidade de Teresina, capital de Piauí, pois, não está no litoral, o que significa entender que de certo modo, suas condições socioambientais são diferenciadas.
} 


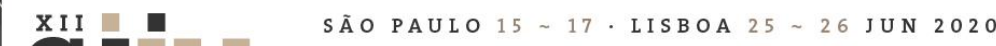

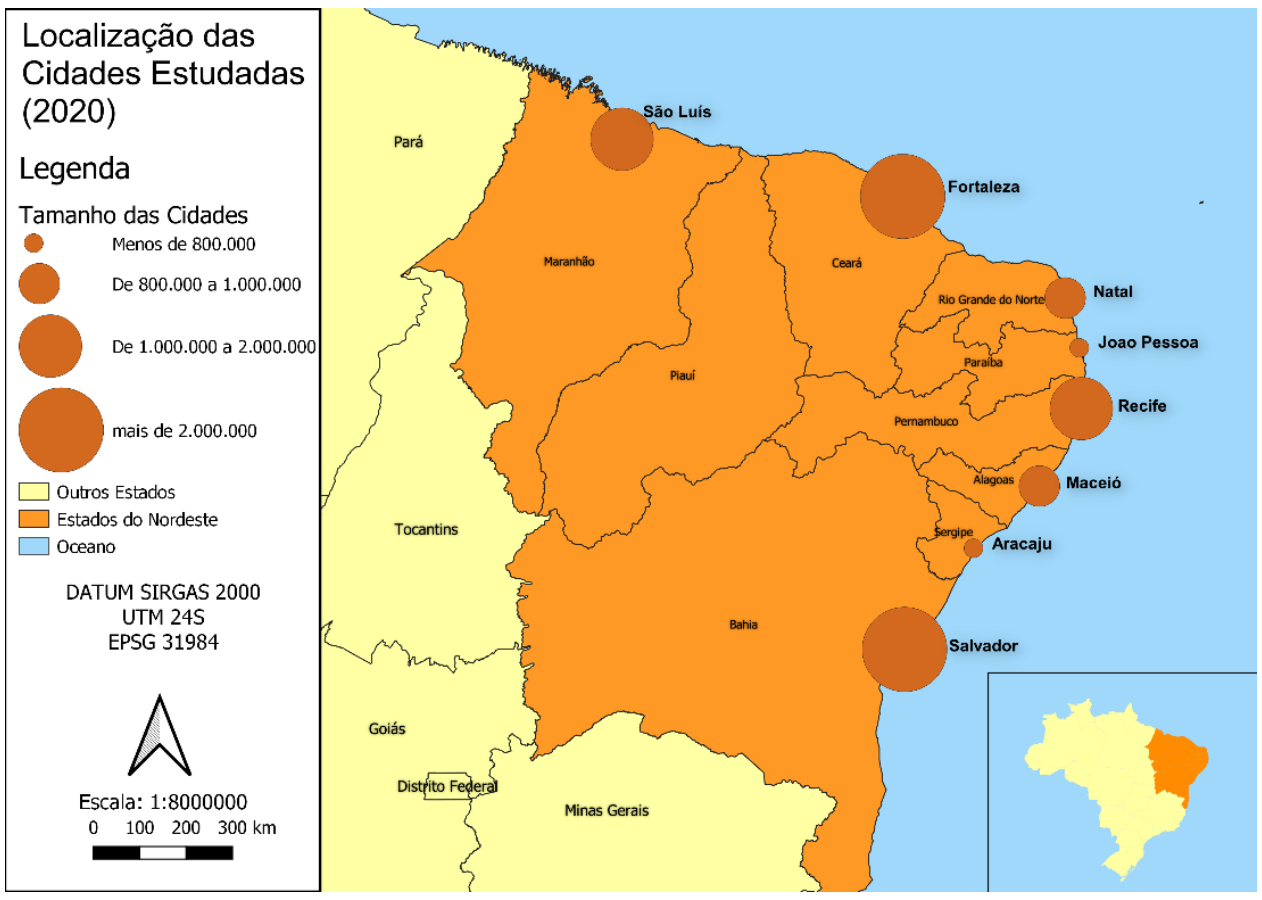

Fig. Mapa de localização das cidades estudadas. Fonte: Elaboração própria segundo dados da legenda.

Como se pode observar, estas cidades litorâneas têm uma certa diferenciação no seu tamanho populacional, muito por decorrência do papel histórico que têm desempenhado nas etapas da vida nacional na rede urbana regional. Nesse sentido, também, entende-se que pensar o meio ambiente é pensar, de modo sistémico e transdisciplinar, a realidade como um ecossistema que tem seus próprios modos de regulação social, políticoinstitucional, econômico-cultural, urbano-ambiental, entre outras dimensões da complexa relação do meio natural e do meio antrópico (Morin, 2013), justamente na associação de componentes sócio-espaciais, sócioambientais (Sousa, 2019) interesse do conhecimento urbano.

O recorte temporal considera os dados disponíveis, principalmente, na Pesquisa MUNIC/IBGE, para os anos 2002, 2009 e 2017; com base nesta pesquisa, é assumida a expressão administrações locais para identificar a estrutura administrativa municipal. Tais dados são posteriormente examinados nas páginas institucionais das respectivas cidades, de modo a apresentar uma perspectiva geral atualizada até 2020.

Então, para compreender a realidade destas cidades, identificam-se três tipos ou grupos de variáveis relacionadas com a assimilação dos princípios de governança, duas delas para contextualizar, no tempo, a criação do órgão e do conselho de gestão do meio ambiente; e o outro conjunto para identificar a política, planos e legislação complementar, inclusive na valorização da interface urbana e ambiental. Os dados e aprofundamento destas variáveis se complementam e se sistematizam, com dados de outras instituições e sites das prefeituras de cada uma das cidades.

É conhecido que a preocupação com a questão sócio-ambiental só entra na pauta das discussões acadêmicas e da gestão pública, na década de 1970, em decorrência da Conferência das Nações Unidas e da publicação do documento 'Os Limites do crescimento', como informam, entre outros, Pott e Estrela (2017). 


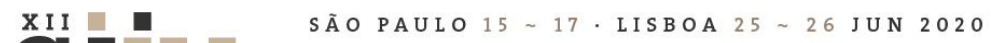 \\ Seminário Internacional de \\ Seminario Internacional de \\ Investigação em Urbanismo \\ Investigación en Urbanismo}

Equivale a dizer que após dois séculos de intensa industrialização e extração de recursos naturais, só faz apenas quarenta anos que a humanidade começa a perceber as implicações da sua relação com a natureza.

As mesmas autoras contribuem para entender que, nessa curta trajetória, ainda parece haver um preocupante padrão no qual, "desastres ambientais, com consequentes contaminações ambientais, atingindo centenas de pessoas antecedem a mobilização da sociedade e tomadas de decisão, ou seja, primeiro têm-se descaracterização de ambientes e perdas [de] vidas humanas e depois de um período de tempo, por vezes anos, chegam as soluções" (Pott; Estrela, 2017: 278). Portanto, instituir e legitimar objetivos e metas na Agenda 2030 é a oportunidade para potencializar processos de urbanização inclusiva, fortalecer os instrumentos de planejamento com controle social e participação dos diversos atores sociais, como divulgado pelo IPEA (2019). É uma estratégia que também fortalece a governança através de instrumentos como os conselhos.

De modo geral, os conselhos estabelecidos nas três escalas federadas em vários setores das políticas públicas são instrumentos ou espaços de governança, como colegiados que garantem representatividade de atores e interesses, em articulação com o órgão de gestão e outros instrumentos legislativos, com competências que podem ser apenas consultivas, até definição normativa, decisórias ou deliberativas (Medina-Velasco, 2004). Na Política Nacional de Meio Ambiente (art. 8o Lei 6938/1981), o papel do conselho (CONAMA) relaciona-se com normas, critérios e padrões de licenciamento, acordos, penalidades, estudos de impacto ambiental, benefícios fiscais e todo o relativo ao controle e à manutenção da qualidade ambiental, vigente ainda neste ano de 2020, embora intensos ajustes à lei, ao longo da sua história. Entende-se que sobre algumas dessas ações está alicerçado o funcionamento dos conselhos no âmbito municipal das cidades estudadas.

Cabe esclarecer que a articulação entre as categorias em foco, governança e questões sócio-ambientais ou sócio-espaciais, exprime um posicionamento crítico à predominância da lógica do mercado na vida urbana. Cientes que esta opção terminológica apenas enfatiza o componente social, que a rigor, segundo Sousa (2019) poderia prescindir-se, pois, direta ou indiretamente, todo espaço, assim como a categoria ambiente, são determinadas dialeticamente pelas relações sociais. Portanto, com base em contribuições complementares (Morin, (2013; Sousa 2019), procura-se assimilar uma perspectiva metodológica, exploratória, sistêmica, crítica, aberta e plural que reconhece o permanente movimento e transformação das pautas do poder público e da sociedade, atentando para as peculiaridades locais, condições de vida, cultura institucional, complexidade e multiplicidade de determinantes que expressam a realidade destas oito cidades do estudo.

\section{Resultados e discussão}

Para apresentar os resultados, análises comparativas e discussão sobre a forma como os oito núcleos urbanos se estão estruturando para cuidar das questões ambientais, interessa caracterizar, primeiramente, cada uma delas nos seus aspectos demográficos e sociais de modo geral, para entender a realidade sócioespacial e suas condições de vida, a partir de alguns dados oficiais, como se apresenta na tabela 1. 


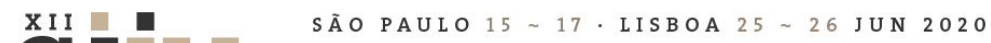 \\ Seminário Internacional de \\ Seminario Internacional de \\ Investigação em Urbanismo \\ Investigación en Urbanismo}

\begin{tabular}{lcccccccc} 
Cidade & Ano instal. & População & $\begin{array}{r}\text { Área urbana } \\
\mathbf{K m}^{2}\end{array}$ & $\begin{array}{r}\text { Dens. } \\
\text { Hab/Km }\end{array}$ & $\begin{array}{l}\text { IDHM } \\
\text { Gida }\end{array}$ & $\begin{array}{c}\text { Esper. de } \\
\text { vida }\end{array}$ & $\begin{array}{c}\text { Mortal. } \\
\text { Infantil }\end{array}$ & $\begin{array}{c}\text { Índice } \\
\text { Gini }\end{array}$ \\
\hline Aracaju & 1855 & 571149 & 167,25 & 3413,67 & 0,770 & 74,4 & 15,6 & 0,62 \\
\hline Fortaleza & 1725 & 2452185 & 320,12 & 7645,29 & 0,754 & 74,4 & 15,8 & 0,61 \\
\hline João Pessoa & 1586 & 723515 & 214,06 & 3379,96 & 0,763 & 74,9 & 16,4 & 0,62 \\
\hline Maceió & 1815 & 932748 & 516,46 & 1805,77 & 0,721 & 72,9 & 22,0 & 0,63 \\
\hline Natal & 1599 & 803739 & 171,15 & 4696,53 & 0,763 & 75.1 & 14,4 & 0,61 \\
\hline Recife & 1709 & 1537704 & 217,01 & 7082,32 & 0,772 & 74,5 & 15,6 & 0,68 \\
\hline Salvador & 1549 & 2675656 & 319,86 & 8368,05 & 0,759 & 75,1 & 14,9 & 0,63 \\
\hline São Luís & 1612 & 1014837 & 563,44 & 1796,01 & 0,768 & 73,8 & 18,1 & 0,61
\end{tabular}

Tabela 1. Caracterização geral das cidades selecionadas. Fonte: elaboração própria a partir dos dados do Censo de 2010 sistematizados pelo IPEA (2013).

Observa-se que o núcleo urbano mais antigo,, têm também maior número de habitantes, com maior densidade populacional, justamente a capital mais próxima espacialmente;realidades sócio-espaciais complexas marcadas pelas desigualdades. Os indicadores relacionados com o Índice de Desenvolvimento Humano Municipal (IDHM), colocam a cidade de Maceió em situação mais preocupante (IPEA, 2013), pois, não só apresenta indicador mais baixo (embora capitais tenham classificação alta), mas também, indicadores de esperança de vida e mortalidade infantil revelam desigualdades nesta cidade. Com melhor situação, estariam as cidades de Natal (dois melhores indicadores), Recife e Salvador (um indicador em destaque). Atenta-se para a desigualdade no Índice Gini na cidade de Recife, distante das outras. De fato, a desigualdade é característica geral das cidades capitais no Nordeste, quando comparadas com a cidade de menor desigualdade de renda no Brasil. ${ }^{3}$

Os oito núcleos urbanos deste estudo foram erguidos como unidades administrativas municipais no ano de 1939 (MUNIC/IBGE, 2017), em uma conjuntura de fortalecimento do aparelho de Estado brasileiro. Contudo, uma das primeiras e mais importantes reflexões a discutir neste trabalho é sobre a atrasada e vagarosa forma como se fortalecem tais estruturas para atender as demandas sócio-ambientais, assim como, de outras políticas públicas. Embora o Brasil seja regido historicamente por um modelo federal, as estruturas municipais só começam atuação efetiva nas políticas públicas, a partir da aprovação da Constituição de 1988, e mesmo assim, com processos, ritmos, e fluxos diferenciados em cada setor políticas (Medina-Velasco, 2004). Para entender o processo de transformações e estruturação destas cidades para cuidar das questões socioambientais, apresenta-se a análise dos três grupos de variáveis em três quadros. O cenário de surgimento e fortalecimento dos órgãos (em geral secretarias municipais), pode-se observar no quadro 1.

\footnotetext{
${ }^{3}$ São Caetano do Sul (SP) com IDHM de 0,862 e Índice Gini 0,54. Segundo o IPEA (2013) o Índice de Gini é "um instrumento usado para medir o grau de concentração de renda. Ele aponta a diferença entre os rendimentos dos mais pobres e dos mais ricos. Numericamente, varia de 0 a 1, sendo que 0 representa a situação de total igualdade, ou seja, todos têm a mesma renda, e o valor 1 significa completa desigualdade de renda, ou seja, se uma só pessoa detém toda a renda do lugar".
} 


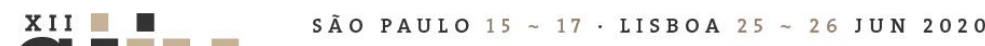

\begin{tabular}{|c|c|c|c|}
\hline \multirow{2}{*}{ Cidades } & \multicolumn{3}{|c|}{ Evolução do órgão segundo dados Munic } \\
\hline & 2002 & 2009 & 2017 \\
\hline Aracaju & Simil. & Sub. & Excl. \\
\hline Fortaleza & Conj. & Conj. & Conj. \\
\hline $\begin{array}{l}\text { João } \\
\text { Pessoa }\end{array}$ & Excl. & Excl. & Excl. \\
\hline Maceió & Excl. & Excl. & Sub. \\
\hline Natal & Conj. & Conj. & Conj. \\
\hline Recife & Conj. & Conj. & Conj. \\
\hline Salvador & Excl. & Conj. & Conj. \\
\hline São Luís & Conj. & Excl. & Excl. \\
\hline
\end{tabular}

\begin{tabular}{|cl|}
\hline $\begin{array}{l}\text { Ano de } \\
\text { criação }\end{array}$ & $\begin{array}{l}\text { Nome da Secretaria Municipal... do setor em } \\
\mathbf{2 0 2 0}\end{array}$ \\
\hline 2013 & ...do Meio Ambiente \\
\hline 2013 & ...de Urbanismo e Meio Ambiente \\
\hline 2002 & ...de Meio Ambiente \\
\hline 2016 & ...de Desenvolvimento Territorial e Meio Ambiente \\
\hline 2018 & ...de Meio Ambiente e Urbanismo \\
\hline 2009 & ...de Meio Ambiente e Urbanismo \\
\hline 2012 & ...Sustentabilidade, Inovação e Resiliência \\
\hline 2007 & ...de Meio Ambiente \\
\hline
\end{tabular}

Quadro 1. Evolução dos instrumentos de gestão sócio-ambiental (2002, 2009 e 2017). Fonte: Elaboração própria a partir dos dados da MUNIC/IBGE e dados das páginas institucionais das cidades. Nota - Tipos de órgãos: Excl.: exclusiva; Conj.: conjunta; Sub.: Setor Subordinado.

No quadro 1, pode-se perceber que as cidades estruturam seu órgão ambiental só no Século XXI, ainda com caráter, papéis e alcances diversos. O órgão exclusivo mais antigo está em João Pessoa e a (re)estruturação mais recente é a de Natal. Em três cidades se mantém o mesmo órgão estabelecido desde começo do Século. Quando considerado o caráter ou alcance, identificam-se quatro cidades com órgão específico para cuidar exclusivamente do setor e, ainda é constatado que, na metade das cidades, as questões ambientais são conjuntamente gerenciadas no mesmo órgão que cuida do desenvolvimento urbano, revelando uma interessante aproximação no tratamento do sócio-espacial e sócio-ambiental. Observam-se duas singularidades: de um lado, a denominação diferenciada do órgão gestor de Salvador, pois no site da própria prefeitura aparece identificado como: "SECIS - Secretaria Municipal de Sustentabilidade, Inovação e Resiliência", e de outro lado, o movimento de integração em Maceió, que em 2002 teve uma secretaria exclusiva, e em 2017 passa a ser parte daquela que cuida do urbano. Os dois casos, guardadas as especificidades, podem ser assimilados como um importante movimento de articulação de princípios e funções, superando a fragmentação da realidade sócio-ambiental.

As informações levantadas na MUNIC/IBGE permitem afirmar que já no início do Século XXI, nas cidades estudadas, a sociedade se mobiliza através de instrumentos de governança e da participação dos diversos atores preocupados com as questões sócio-ambientais. Assim, os conselhos parecem ganhar visibilidade, especialmente, com relação ao licenciamento e por isso foram analisados como o segundo tipo de variável, conforme se observa no quadro 2. 


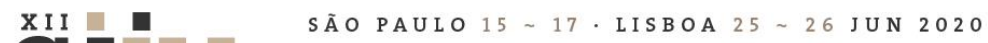 \\ Seminário Internacional de Investigação em Urbanismo

\begin{tabular}{|c|c|c|c|c|c|c|c|c|}
\hline \multirow[t]{2}{*}{ Cidades } & \multicolumn{3}{|c|}{ Conselho } & \multicolumn{3}{|c|}{ Licenciamento } & \multirow{2}{*}{$\begin{array}{l}\text { Sigla do Conselho Municipal do Meio } \\
\text { Ambiente }\end{array}$} & \multirow[t]{2}{*}{ Caráter do conselho } \\
\hline & 2002 & 2009 & 2017 & 2002 & 2009 & 2017 & & \\
\hline \multirow[t]{2}{*}{ Aracajú } & & * & * & - & - & * & CMMA & Consultivo \& deliberativo \\
\hline & & & & & & & Lei $4378 / 2013$ & \\
\hline \multirow[t]{2}{*}{ Fortaleza } & * & * & * & - & - & * & COMAM & Deliberativo \\
\hline & & & & & & & Lei $8048 / 1997$ & \\
\hline \multirow{2}{*}{$\begin{array}{l}\text { João } \\
\text { Pessoa }\end{array}$} & - & * & * & - & * & * & COMAM & Consultivo, normativo \& \\
\hline & & & & & & & Lei Complementar 29/2002 & \\
\hline \multirow[t]{2}{*}{ Maceió } & * & * & * & - & - & - & COMPRAM & Deliberativo \\
\hline & & & & & & & Lei 4214/1993 & \\
\hline \multirow[t]{2}{*}{ Natal } & * & * & * & - & - & - & CONPLAM $^{1}$ & Consultivo \& normativo \\
\hline & & & & & & & Lei 2.211/1974 & \\
\hline \multirow[t]{2}{*}{ Recife } & & * & * & - & * & * & COMAM & Consultivo, normativo \& \\
\hline & & & & & & & Lei $17534 / 1992$ & deliberativo \\
\hline \multirow[t]{2}{*}{ Salvador } & * & * & * & - & - & * & COMAM & Consultivo, normativo \& \\
\hline & & & & & & & Dec. 16940/2006 & \\
\hline \multirow[t]{2}{*}{ São Luís } & & * & * & - & - & * & COMUM & Consultivo, normativo \& \\
\hline & & & & & & & Lei 4739/2006 & \\
\hline
\end{tabular}

No quadro 2, observa-se que em 2002, metade das cidades tinham seu conselho de meio ambiente e a partir de 2009, é incorporado na gestão de todas as cidades estudadas. Também se pode perceber a tendência das administrações destas cidades em assumir os processos de licenciamento; observe-se que em 2002, apenas uma cidade (João Pessoa) tinha este controle, enquanto em 2017, apenas Maceió e Natal ainda não assumiram esta tarefa, uma das principais adotadas pelos próprios conselhos. Isto revela um processo de fortalecimento na estruturação do setor nos processos de governança, onde incorporam-se órgãos consultivos, na maioria dos casos deliberativos, contudo, só em Fortaleza e Salvador evidencia-se alguma dinâmica destes, até o ano 2018. 


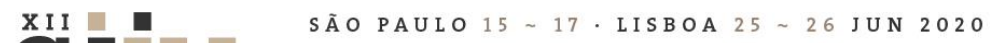 \\ Seminário Internacional de Investigação em Urbanismo \\ Seminario Internacional de Investigación en Urbanismo}

Com relação à política e planos do setor e das interfaces, revela-se uma tendência diversificada e lenta nas cidades estudadas. Ressalta-se que o Plano Diretor em duas das cidades foi formulado antes do Estatuto da Cidade (Lei 10257/2001), no caso de Aracaju, não se revela nenhuma atualização. Cinco cidades elaboraram suas diretrizes de desenvolvimento urbano, na primeira década do Século XXI e só uma formulou um novo plano nesta última década (Salvador em 2016). Para entender a trajetória de assimilação destes e outros instrumentos socioambientais, apresenta-se o levantamento no quadro 3.

\begin{tabular}{|c|c|c|c|}
\hline Cidades & $\begin{array}{l}\text { Plano Diretor } \\
\text { criação/revis. } \\
\text { inf. até } 2018\end{array}$ & Política Municipal de Meio Ambiente & $\begin{array}{l}\text { Outras disposições de política e planos municipais } \\
\text { complementares ou relacionados à gestão do Meio Ambiente }\end{array}$ \\
\hline Aracaju & 2000/não & - & $\begin{array}{l}\text { Lei 1789/1992 - Código de proteção ambiental } \\
\text { Lei } 2788 / 2000 \text { - Política de Saneamento } \\
\text { Lei } 3309 / 2005 \text { - Política de Educação Ambiental } \\
\text { Lei } 543 / 77 \text { - Plano de Arborização }\end{array}$ \\
\hline Fortaleza & 2009/não & $\begin{array}{l}\text { Lei } 10619 / 2017 \\
\text { Política Municipal do Meio Ambiente }\end{array}$ & $\begin{array}{l}\text { Dec.13713/2015 - Plano de Saneamento Básico } \\
\text { Lei 10586/2017 - Política de Desenv. Urbano de Baixo Carbono }\end{array}$ \\
\hline $\begin{array}{l}\text { João } \\
\text { Pessoa }\end{array}$ & 1992/sim & - & $\begin{array}{l}\text { Lei Com. 29/2002 - Código de Meio Ambiente } \\
\text { Decr. 7784/2012 - Cria Comitê de monitoramento da gestão/ODMs } \\
\text { Lei Com. 93/2015 - Política de Saneamento Básico } \\
\text { Lei Com. 100/2016 - Código Sanitário do Município } \\
\text { Dec. 8886/2016 - Política de Resíduos Sólidos }\end{array}$ \\
\hline Maceió & 2005/não & - & $\begin{array}{l}\text { Lei 4548/1996 - Código do Meio Ambiente } \\
\text { Decr. 6429/2004 - Sistema de Meio Ambiente } \\
\text { Lei 6755/2018 - Política de Saneamento }\end{array}$ \\
\hline Natal & $2007 / \operatorname{sim}$ & - & $\begin{array}{l}\text { Lei 4100/1992 - Código do Meio Ambiente } \\
\text { Lei Com. 124/2011 - Plano Diretor Dren. e Manejo de Águas Pluv. }\end{array}$ \\
\hline Recife & 2008/não & $\begin{array}{l}\text { Lei } 16243 / 1996 \\
\text { Política do Meio Ambiente }\end{array}$ & $\begin{array}{l}\text { Dec. 27045/2013 - Plano Metrop.de Resíduos Sólidos } \\
\text { Lei 18014/2014 - Sistema de Unidades Protegidas } \\
\text { Lei 18208/2015 - Política de Saneamento Básico }\end{array}$ \\
\hline Salvador & 2016/não & $\begin{array}{l}\text { Lei } 8915 / 2015 \\
\text { Política Municipal de Meio Ambiente e } \\
\text { Desenvolvimento Sustentável }\end{array}$ & Lei 9187/2017 - Plano Diretor de Arborização \\
\hline São Luís & $2006 / \mathrm{sim}$ & $\begin{array}{l}\text { Lei } 4738 / 2006 \\
\text { Política Municipal de Meio Ambiente }\end{array}$ & $\begin{array}{l}\text { Lei 4516/2005 - Política de Saneamento } \\
\text { Leo 5636/2012 - Sistema de unidades de Conservação }\end{array}$ \\
\hline
\end{tabular}

Quadro 3. Principais instrumentos legais no setor do meio ambiente nas cidades selecionadas. Fonte: Elaboração própria a partir da MUNIC/IBGE e dos sites das administrações municipais das cidades escolhidas. Nota: -: Sem política específica sobre Meio Ambiente. 


\section{XII $\quad$ SÃO PAULO 15 $\sim 17 \cdot$ LISBOA $25 \sim 26$ JUN 2020 \\ Seminário Internacional de \\ Seminario Internacional de Investigação em Urbanismo

Como se pode observar no quadro 3 , a assimilação de uma política ambiental retrata a dispersão na incorporação de instrumentos normativos, para o setor, nas cidades estudadas. Justo, a metade das cidades estudadas têm explicitamente estabelecida uma política para o setor: Recife de modo antecipado (1996), duas na primeira década do Século XXI, as mais recentes são Salvador e Fortaleza. Aquelas que não têm política, têm o Código aprovado antes de 2002. Isso significa que as cidades têm legitimado sua política setorial, também implantado outras, junto com planos complementares, com diversidade de enfoques. Interessa destacar que seis cidades já têm formulado sua política ou seu Plano de Saneamento, apenas em Salvador e Natal não se encontrou disposição de aprovação, ainda, deste instrumento obrigatório por lei federal. Mesmo identificando algumas medidas particulares sobre resíduos sólidos, em nenhuma das cidades foi identificada política ou plano obrigatórios. Interessa também, para as finalidades deste trabalho, registrar que quatro das oito cidades estudadas (Fortaleza, Recife, Salvador e São Luís) são signatárias do Programa Cidades Sustentáveis (PCS, 2020), iniciativa promovida por algumas Organizações Não Governamentais (ONGs), desde o ano 2010 no Brasil.

Com relação ao papel de cidades litorâneas, tendo como base as diretrizes federais do Plano Nacional de Gerenciamento Costeiro (Lei 7661/1988, art. $5^{\circ}$ ), onde estabelece que estados e municípios poderão instituir os respectivos planos atendendo às disposições federais que podem coincidir com a Agenda 2030, vale registrar que somente Aracaju consta com Plano de Gerenciamento Integrado, entende-se que por iniciativa federal (MMA,2020). É, também, a única cidade com política específica de educação ambiental, ferramenta estratégica para orientar a atuação da sociedade. Aparecem disposições direcionadas para arborização nas cidades de Aracaju (sem norma) e Salvador. Neste último caso, destaca-se a iniciativa de um observatório para o monitoramento das ações de sustentabilidade (sem norma). No âmbito da esfera federal, encontramse evidências de programas ${ }^{4}$ sem aparente articulação, não apenas com as metas dos ODSs, mas com outros espaços de governança sócio-ambiental.

Apresentadas as três variáveis do estudo (órgãos, conselhos e instrumentos normativos), interessa destacar a questão sócio-ambiental como parte do fortalecimento da governança pública no Brasil, neste início de Século XXI. Embora instrumentos participativos, consagrados pelo Decreto 8243/2014, estejam sendo paulatinamente extinguidos (Decretos 9759/2019; 9812/2019) pelo governo federal, que parece limitar a atuação dos órgãos colegiados tais como os conselhos, comitês, comissões, grupos, juntas, equipes, mesas, fóruns entre outros espaços de governança e controle social, ainda se preserva a institucionalidade do conselho como espaço colegiado na dinâmica sócio-ambiental.

Qual a visibilidade do conselho nas agendas socioambientais nacionais e locais? Aparentemente pouca, revelando que a dinâmica dos diversos atores sociais também dialoga ou decorre da legitimidade outorgada pelo poder público, especialmente pautada pela esfera federal. ONGs e movimentos ambientalistas, que têm contribuído historicamente nas pautas do setor, parecem estar retrocedendo, diminuindo visibilidade ou impacto no seu papel de controle social.

Pode-se confirmar que a mobilização da sociedade, com relação às questões ambientais, além de ter traços de dispersão, irregularidade, como afirma Sousa (2019), a trajetória histórica desse ativismo social tem variedade temática, de escala e impacto, de acordo proponho conjunturas nacionais e, poderia se

\footnotetext{
${ }^{4}$ Faz-se referência à 'Agenda Nacional de Qualidade Ambiental Urbana', programa estabelecido pelo Ministério de Meio Ambiente "com o objetivo de melhorar os indicadores da boa qualidade ambiental nas cidades. Com foco na população residente nas grandes metrópoles" (MMA, 2020), considerando seis linhas de ação com metas específicas: Lixo no Mar, Resíduos Sólidos, Áreas Verdes Urbanas, Qualidade do Ar, Saneamento e Qualidade das Águas, e Áreas Contaminadas.
} 


\section{XII \\ Seminário Internacional de \\ Seminario Internacional de Investigação em Urbanismo

acrescentar, regionais e locais, como expressão de cultura política e dinâmica das próprias organizações sociais e da vida social. Cidades como Maceió e São Luís, e muitas comunidades urbanas destas oito cidades, ainda se denotam muito mais preocupadas com questões básicas de sobrevivência. Indignação e posicionamento crítico decorrentes de processos de educação e consciência são bases para a formação cidadã, contudo, é a práxis, no entorno da vida pública, onde se materializa a cidadania ativa e com relação a isso parece haver um compromisso a trilhar nas oito cidades.

A preocupação com a articulação entre administrações locais e sociedade, amplia-se à escalas superiores, considerando que as oito cidades capitais são parte de Regiões Metropolitanas, para as quais o Estatuto da Metrópole (Lei 13089/2015) estabelece a governança interfederativa, compartilhamento de responsabilidades e ações entre esferas. Em outras regiões e cidades, o poder público tende a dialogar com esforços vindos das diversas motivações dos seus atores sociais, em iniciativas coletivas para a melhoria das condições sócioambientais, inclusive na mobilização da Agenda 2030, experiência a se construir no Nordeste Brasileiro.

Com base nisto, propõe-se que indicadores socio-ambientais e das metas dos ODSs passem a ser plenamente divulgados e acompanhados, não apenas pelos órgãos públicos das diversas esferas, mas principalmente, pelos diversos atores, organizações, movimentos, de modo a entender e se inserir nas decisões mais ativamente, especialmente, no cenário em que se supõe um compromisso coletivo maior com o cuidado das cidades.

\section{Considerações Finais}

A pergunta orientadora desta abordagem - como as administrações locais têm-se estruturado e se aproximado da sociedade para tratar as questões ambientais? - pode ser respondida de modo curto e pouco animador. Com base no levantamento, sistematização e análise das variáveis fica evidenciada a heterogeneidade de instrumentos e níveis de compromisso assimilados em cada uma das oito cidades estudadas.

Todas as cidades estudadas assimilaram órgãos, colegiados e instrumentos normativos, inclusive em alguns casos, com conteúdo embasado nos princípios da sustentabilidade, contudo, denota-se a fragilização dos espaços de governança sócio-ambiental, escassa articulação entre esferas de governo e entre unidades municipais, assim como, difusa incorporação dos objetivos e metas da Agenda 2030, como acontece no Brasil de modo geral. São cidades que ainda parecem não focar a prevenção e a governança nas suas políticas, planos, programas ou ações, embora, existam os riscos e demandas sócio-espaciais.

Comparativamente, percebe-se em Fortaleza, Aracajú e Salvador, algum nível de fortalecimento no tratamento das questões socioambientais, enquanto que, São Luís e Salvador destacam-se como signatárias de programas internacionais, esta última, tendendo a incorporar os ODSs na dinâmica de sua secretaria. Ou seja, de modo geral, instrumentos se instituem em diferentes conjunturas por iniciativas locais. Isto também ajuda a denotar a heterogeneidade de processos e a falta de articulação entre esferas de governo e sociedade, esta última necessária de ser promovida pelas instâncias públicas superiores, através do efetivo funcionamento dos espaços de governança estabelecidos.

Numa perspectiva histórica, significaria dizer que a precocidade com a qual o Brasil define sua Política Nacional de Meio Ambiente (1981) e assume papel relevante na governança sócio-ambiental, no cenário internacional, com a realização da ECO-92, não parece mostrar-se numa linha contínua, articulada e integrada no equacionamento das questões socioambientais, como revela o estudo nas capitais litorâneas do Nordeste brasileiro, com realidade sócio-ambiental evidenciada de modo particular. Deriva disto, a importância do 


\section{SÃOPAULO15 17. LISBOA $25 \sim 26$ JUN 2020 \\ Seminário Internacional de \\ Seminario Internacional de Investigação em Urbanismo

compromisso que as cidades estudadas podem assumir para "aumentar a urbanização inclusiva e sustentável, aprimorar as capacidades para o planejamento, para o controle social e para a gestão participativa, integrada e sustentável dos assentamentos humanos”, segundo Agenda 2030.

O modelo federativo pode sim, fortalecer a autonomia municipal e, à vez, promover maior articulação entre esferas e atores locais, nos assuntos ambientais, em um país de tamanho e diversidade territorial como o Brasil. Entende-se que é nas cidades onde se evidenciam, mobilizam e se encontram os cidadãos que querem, precisam e poderiam (a partir de suas práticas cotidianas) se engajar, mais diretamente, com as questões sócio-ambientais do seu entorno, no seu dia-dia. Nesse sentido, o recado deste trabalho está direcionado a fortalecer redes de relação em todas as escalas da vida sócio-espacial e da institucionalidade normativa, para agregar forças e partilhar experiências em torno a uma questão que está na base da sobrevivência da espécie humana. Acompanhar, ampliar, contribuir e aprofundar transformações futuras é um compromisso acadêmico, especialmente, nesta conjuntura de explicitação de vulnerabilidades sócioambientais.

\section{BIBLIOGRAFIA}

\section{Obras completas}

DE SOUSA, M. LOPES. (2019). Ambientes e territórios. Rio de Janeiro: Bertrand.

MEDINA-VELASCO, M. (2004) Descentralização e Política Urbana em Municípios de Porte Médio: o caso de Barreiras e Alagoinhas (Ba). Tese de Doutorado. Faculdade de Arquitetura e Urbanismo da Universidade de São Paulo, São Paulo.

MORIN, E. (2013) A Via para o futuro da humanidade. Rio de Janeiro: Bertrand.

\section{Capítulo de livro}

LEME, T. N. (2016). Governança ambiental no nível municipal. Em: Moura, A. Governança Ambiental no Brasil. Brasília: Ipea.

POTT, C.; ESTRELA, C. (2017) Histórico ambiental: desastres ambientais e o despertar de um novo pensamento. Estudos Avançados, v. 31, n. 89, p. 271-283, São Paulo.

\section{Leis e decretos em fontes eletrônicas}

Constituição da República Federativa do Brasil de 1988 (1988). Brasília. http://www.planalto.gov.br/ccivil_03/constituicao/constituicao.htm (consulta: 20/02/2020).

Decreto $n^{\circ}$ 13.713, de 18 de dezembro de 2015 (2015). Aprova o Plano Municipal de Saneamento Básico, nas modalidades resíduos, abastecimento de água, esgotamento sanitário e drenagem, no município de Fortaleza, e dá outras providências. https://leismunicipais.com.br/a/ce/f/fortaleza/decreto/2015/1371/13713/decreto-n-13713-2015-aprova-oplano-municipal-de-saneamento-basico-nas-modalidades-residuos-abastecimento-de-agua-esgotamentosanitario-e-drenagem-no-municipio-de-fortaleza-e-da-outras-providencias (consulta: 20/02/2020).

Decreto $n^{\circ} 6.429$ de 02 de julho de 2004 (2004). Dispõe sobre o funcionamento do sistema municipal de meio ambiente e da outras providências. Maceió. http://www.maceio.al.gov.br/wp- 


\section{SÃOPAULO15 17 LISBOA $25 \sim 26$ JUN 2020 \\ Seminário Internacional de \\ Seminario Internacional de Investigação em Urbanismo

content/uploads/2018/03/pdf/2018/03/decreto-6.429-2004-sistema-municipal-de-meio-ambiente (consulta: 20/02/2020).

Decreto $n^{\circ} 7.784$ de 27 de dezembro de 2012 (2012). Cria o Comitê Municipal técnico de monitoramento das atividades da gestão municipal voltadas aos objetivos de desenvolvimento do milênio - ODM na Paraíba, e da outras providências. João Pessoa. http://antigo.joaopessoa.pb.gov.br/portal/wpcontent/uploads/2013/03/decreto-odm.pdf (consulta: 20/02/2020).

Decreto no 16.940, de 10 de novembro de 2006 (2006). Aprova o Regimento do Conselho Municipal do Meio Ambiente do Município do Salvador. https://leismunicipais.com.br/a2/ba/s/salvador/decreto/2006/1694/16940/decreto-n-16940-2006-aprova-oregimento-do-conselho-municipal-do-meio-ambiente-do-municipio-do-salvador-comam (consulta: 20/02/2020).

Decreto oㅡ 27.045, de 19 de abril de 2013 (2013). Reconhece o Plano Metropolitano de Resíduos Sólidos pmrs da região metropolitana como plano municipal de gestão integrada de resíduos sólidos... Recife. https://leismunicipais.com.br/a1/pe/r/recife/decreto/2013/2705/27045/decreto-n-27045-2013-reconhece-oplano-metropolitano-de-residuos-solidos-pmrs-da-regiao-metropolitana-como-plano-municipal-de-gestaointegrada-de-residuos-solidos-do-municipio-do-recife?q=27045 (consulta: 20/02/2020).

Decreto ํo 5.377 de 23 de fevereiro de 2005 (2005). Aprova a Política Nacional para os Recursos do Mar. Brasília. http://www.planalto.gov.br/ccivil_03/_ato2004-2006/2005/decreto/d5377.htm (consulta: 20/02/2020).

Decreto no 8.243, de 23 de maio de 2014 (2014). Institui a Política Nacional de Participação Social... Brasília. http://www.planalto.gov.br/ccivil_03/_ato2011-2014/2014/decreto/d8243.htm (consulta: 20/02/2020).

Decreto no 8.886 de 23 de dezembro de 2016 (2016). Dispõe sobre a Política Municipal de Resíduos Sólidos do município de João Pessoa e dá outras providências. João Pessoa. https://www.legisweb.com.br/legislacao/?id=334658 (consulta: 20/02/2020).

Decreto no 9.759, de 11 de abril de 2019 (2019). Extingue e estabelece diretrizes, regras e limitações para colegiados da administração pública federal. Brasília. http://www.planalto.gov.br/ccivil_03/_ato20192022/2019/decreto/d9759.htm (consulta: 20/02/2020).

Decreto no 9.812, de 30 de maio de 2019 (2019). Altera o decreto oㅜ 9.759, de 11 de abril de 2019, que extingue e estabelece diretrizes, regras e limitações para colegiados da administração pública federal. Brasília. http://www.planalto.gov.br/ccivil_03/_ato2019-2022/2019/decreto/d9812.htm (consulta: 20/02/2020).

Lei Complementar 124 de 2011 (2011) - Institui Plano Diretor Drenagem e Manejo de Águas Pluviais. Natal. http://Irengenhariaeconsultoria.com.br/planodiretor/04-lei-complementar-n124/lei-complementar-124 (consulta: 20/02/2020).

Lei Complementar ํo 100, de $1^{\circ}$ de julho de 2016 (2016). Institui o Código Sanitário do Município de João Pessoa, e dá outras providências. João Pessoa. https://leismunicipais.com.br/a/pb/j/joao-pessoa/leicomplementar/2016/10/100/lei-complementar-n-100-2016-institui-o-codigo-sanitario-do-municipio-de-joaopessoa-e-da-outras-providencias (consulta: 20/02/2020). 


\section{XII $\quad$ SÃO PAULO 15 $\sim 17 \cdot$ LISBOA $25 \sim 26$ JUN 2020 \\ Seminário Internacional de \\ Seminario Internacional de Investigação em Urbanismo

Lei Complementar ํㅡ 29, de 05 de agosto de 2002 (2002). Institui o código de meio ambiente do município de João Pessoa. https://leismunicipais.com.br/a/pb/j/joao-pessoa/lei-complementar/2002/2/29/lei-complementarn-29-2002-institui-o-codigo-de-meio-ambiente-do-municipio-de-joao-pessoa-e-dispoe-sobre-o-sistemamunicipal-de-meio-ambiente-sismuma (consulta: 20/02/2020).

Lei Complementar o 93, de 30 de dezembro de 2015 (2015). Dispõe sobre a Política Municipal de Saneamento básico do município de joão pessoa, seus instrumentos, e dá outras providências. João Pessoa. https://leismunicipais.com.br/a/pb/j/joao-pessoa/lei-complementar/2015/9/93/lei-complementar-n-93-2015dispoe-sobre-a-politica-municipal-de-saneamento-basico-do-municipio-de-joao-pessoa-seus-instrumentos-eda-outras-providencias (consulta: 20/02/2020).

Lei n.o 18.014, de 2014 (2014). Institui o Sistema Municipal de Unidades Protegidas - Recife. https://leismunicipais.com.br/a1/pe/r/recife/lei-ordinaria/2014/1801/18014/lei-ordinaria-n-18014-2014-instituio-sistema-municipal-de-unidades-protegidas-smup-recife-e-da-outras-providencias (consulta: 20/02/2020).

Lei $n .$. 18.208, de 2015 (2015). Dispõe sobre a Política Municipal de Saneamento Básico, cria o Sistema municipal de Saneamento Básico [entre outras]. Recife. https:/leismunicipais.com.br/a1/pe/r/recife/leiordinaria/2015/1820/18208/lei-ordinaria-n-18208-2015-dispoe-sobre-a-politica-municipal-de-saneamentobasico-cria-o-sistema-municipal-de-saneamento-basico-e-institui-os-elementos-para-elaboracao-do-planomunicipal-de-saneamento-basico-do-recife-destinado-a-promover-a-saude-a-qualidade-de-vida-e-do-meioambiente-a-organizar-a-gestao-e-estabelecer-as-condicoes-para-prestacao-dos-servicos-publicos-desaneamento-basico-e-sua-

universalizacao\#: :text=1\%c2\%ba\%20esta\%20lei\%20institui\%20a,b\%c3\%a1sico\%20e\%20outras\%20norm as\%20aplic\%c3\%a1veis (consulta: 20/02/2020).

Lei n.․ 4.100, de 19 de junho de 1992. Dispõe sobre o Código do Meio Ambiente do município do Natal. Natal. https://www.natal.rn.gov.br/bvn/publicacoes/lei_n_4100 (consulta: 20/02/2020).

Lei n.․ 4.516, de 27 de julho de 2005 (2005). Dispõe sobre as Política Municipal de Saneamento. São Luís. https://leismunicipais.com.br/a/ma/s/sao-luis/lei-ordinaria/2005/452/4516/leiordinaria-n-4516-2005-dispoesobre-as-politica-municipal-de-saneamento (consulta: 20/02/2020).

Lei n.. 4.548, de 21 de novembro de 1996 (1996). Institui o Código Municipal de Meio Ambiente e dispõe sobre a administração do uso dos recursos ambientais, da proteção da qualidade do meio ambiente, do controle das fontes poluidoras da ordenação do uso do solo do território do município de maceió, de forma a garantir 0 desenvolvimento sustentável. Maceió. http://www.residuossolidos.al.gov.br/vgmidia/arquivos/52_ext_arquivo (consulta: 20/02/2020).

Lei $n .-6.755$, de 24 de maio de 2018 (2018). Estabelece a política municipal de saneamento básico do município de maceió e outras providências. Maceió. http://www.maceio.al.gov.br/wpcontent/uploads/2018/04/pdf/2018/04/lei-n\%c2\%ba-6755-2018-politica-municipal-saneamento-nova-lei (consulta: 20/02/2020).

Lei n. 9.187, de 2017 (2017). Dispõe sobre o Plano Diretor de Arborização Urbana do Município de Salvador. Salvador. https://leismunicipais.com.br/a/ba/s/salvador/lei-ordinaria/2017/919/9187/lei-ordinaria-n-91872017-dispoe-sobre-o-plano-diretor-de-arborizacao-urbana-do-municipio-de-salvador (consulta: 20/02/2020). 


\section{SÃOPAULO15 17 LISBOA $25 \sim 26$ JUN 2020 \\ Seminário Internacional de \\ Seminario Internacional de Investigação em Urbanismo

Lei $n^{\circ}$ 10.257, de 10 de julho de 2001. Regulamenta os arts. 182 e 183 da Constituição Federal, estabelece Diretrizes Gerais da Política Urbana. Brasília. http://www.planalto.gov.br/ccivil_03/leis/leis_2001/10257.htm\#: :text=lei\%20no\%2010.257\%2c\%20de\%201 0\%20de\%20julho\%20de\%202001.\&text=regulamenta\%20os\%20arts.,urbana\%20e\%20d\%c3\%a1\%20outras \%20provid\%c3\%aancias.\&text=art.,de\%20que\%20tratam\%20os\%20arts (consulta: 20/02/2020).

Lei $n^{\circ} 2.211$, de 10 de julho de 1974 (1974). Cria o conselho municipal de planejamento urbano e meio ambiente. Natal. dhttps://www.natal.rn.gov.br/semurb/paginas/ctd-618.html (consulta: 20/02/2020).

Lei no 1.789, de 17 de janeiro de 1992 (1992). Código de Proteção Ambiental do Município de Aracaju. Aracaju. https://leismunicipais.com.br/a/se/a/aracaju/lei-ordinaria/1992/178/1789/lei-ordinaria-n-1789-1992-codigo-deprotecao-ambiental-do-municipio-de-aracaju-e-da-providencias-correlatas (consulta: 20/02/2020).

Lei ํㅜ 10.586, de 13 de junho de 2017 (2017). Dispõe sobre a Política de Desenvolvimento Urbano de Baixo Carbono de Fortaleza. Fortaleza. https:/leismunicipais.com.br/a/ce/f/fortaleza/leiordinaria/2017/1058/10586/lei-ordinaria-n-10586-2017-dispoe-sobre-a-politica-de-desenvolvimento-urbanode-baixo-carbono-de-fortaleza-e-da-outras-providencias (consulta: 20/02/2020).

Lei o 10.619, de 10 de outubro de 2017 (2017). Dispõe sobre política municipal do meio ambiente de fortaleza e dá outras providências. Fortaleza. https://www.legisweb.com.br/legislacao/?id=351732 (consulta: 20/02/2020).

Lei ำ 10.765, de 03 de julho de 2018 (2018). Altera dispositivos da lei oㅜ 8.048, de 24 de julho de 1997, cria o Conselho Municipal de Meio Ambiente. Fortaleza. https://leismunicipais.com.br/a/ce/f/fortaleza/leiordinaria/2018/1077/10765/lei-ordinaria-n-10765-2018-altera-dispositivos-da-lei-n-8048-de-24-de-julho-de1997-que-cria-o-conselho-municipal-de-meio-ambiente-comam-modificados-pela-lei-n-8707-de-19-de-maiode-2003-e-da-outras-providencias. (consulta: 20/02/2020).

Lei oㅜ 13.089, de 12 de janeiro de 2015. Institui o Estatuto da Metrópole, altera a Lei no 10.257, de 10 de julho de 2001. Brasília. http://www.planalto.gov.br/ccivil_03/_ato2015-2018/2015/lei//13089.htm (consulta: 20/02/2020).

Lei oㅜ 16.243, de 1996 (1996). Estabelece a Política do Meio Ambiente da cidade do Recife. Recife. https:/leismunicipais.com.br/a/pe/r/recife/lei-ordinaria/1996/1624/16243/lei-ordinaria-n-16243-1996estabelece-a-politica-do-meio-ambiente-da-cidade-do-recife-e-consolida-a-sua-legislacao-ambientalmediante-a-instituicao-do-codigo-do-meio-ambiente-e-do-equilibrio-ecologico-da-cidade-do-recife (consulta: 20/02/2020)

Lei no 17.534, de 1992 (1992). Dispõe sobre o Conselho Municipal do Meio Ambiente. Recife. http://meioambiente.recife.pe.gov.br/sites/default/files/midia/wysiwyg/arquivos/lei-ordinaria-175342009_revogou_a_15.707.pdf (consulta: 20/02/2020).

Lei $n^{\circ}$ 2.788, de 15 de março de 2000 (2000). Dispõe sobre a Política Municipal de Saneamento, seus instrumentos. Aracaju. https://leismunicipais.com.br/a/se/a/aracaju/lei-ordinaria/2000/278/2788/lei-ordinarian-2788-2000-dispoe-sobre-a-politica-municipal-de-saneamento-seus-instumento-e-da-outrasprovidencias\#: :text=1\%c2\%ba\%20a\%20pol\%c3\%adtica\%20municipal\%20de,e\%20a\%20execu\%c3\%a7\%c 3\%a30\%20das\%20a\%c3\%a7\%c3\%b5es\%2c (consulta: 20/02/2020). 


\section{SÃOPAULO15 17 LISBOA $25 \sim 26$ JUN 2020 \\ Seminário Internacional de \\ Seminario Internacional de Investigação em Urbanismo

Lei no 3.309, de 21 de dezembro de 2005 (2005). Dispõe sobre a Política Municipal de Educação Ambiental e dá outras providências. Aracaju. https://leismunicipais.com.br/a/se/a/aracaju/lei-ordinaria/2005/330/3309/leiordinaria-n-3309-2005-dispoe-sobre-a-politica-municipal-de-educacao-ambiental-e-da-outras-providencias (consulta: 20/02/2020).

Lei $n$ ㅇ 4.214, de 05 de julho de 1993 (1993). Cria a secretaria municipal de meio ambiente. regulamenta o conselho municipal de proteção ambiental. https://www.maceio.al.leg.br/documentos/docs/doc.php?filepath=leis\&id=4289 (consulta: 20/02/2020).

Lei oㅜ 4.739, de 28 de dezembro de 2006 (2006). Dispõe sobre a regulamentação do Conselho Municipal de Meio Ambiente. São Luís. https://leismunicipais.com.br/a/ma/s/sao-luis/lei-ordinaria/2006/473/4739/leiordinaria-n-4739-2006-dispoe-sobre-a-regulamentacao-do-conselho-municipal-de-meio-ambiente-da-outrasprovidencias (consulta: 20/02/2020).

Lei no 4738, de 28 de dezembro de 2006 (2006). Institui a Política Municipal de Meio Ambiente de São Luís. São Luís. https://leismunicipais.com.br/a/ma/s/sao-luis/lei-ordinaria/2006/473/4738/lei-ordinaria-n-47382006-institui-a-politica-municipal-de-meio-ambiente-de-sao-luis-da-outras-providencias 20/02/2020).

Lei oㅜ 543/77, de 14 de outubro de 1977 (1977). Dispõe sobre a Arborização Pública e Defesa das árvores. Aracaju. $\quad$ https://leismunicipais.com.br/a/se/a/aracaju/lei-ordinaria/1977/54/543/lei-ordinaria-n-543-1977dispoe-sobre-a-arborizacao-publica-e-defesa-das-arvores (consulta: 20/02/2020).

Lei oㅜ 6.938, de 31 de agosto de 1981 (1981). Dispõe sobre a política nacional do meio ambiente, seus fins e mecanismos de formulação e aplicação. Brasília. http://www.planalto.gov.br/ccivil_03/leis/l6938.htm (consulta: 20/02/2020).

Lei oㅜ 7.661, de 16 de maio de 1988 (1988). Institui o Plano Nacional de Gerenciamento Costeiro. Brasília. http://www.planalto.gov.br/ccivil_03/leis/l7661.htm (consulta: 20/02/2020).

Lei no 8915, de 2015 (2015). Dispõe sobre a Política Municipal de Meio Ambiente e Desenvolvimento Sustentável; institui o cadastro municipal de atividades potencialmente degradadoras e utilizadoras de recursos naturais. Salvador. https://leismunicipais.com.br/a/ba/s/salvador/lei-ordinaria/2015/891/8915/leiordinaria-n-8915-2015-dispoe-sobre-a-politica-municipal-de-meio-ambiente-e-desenvolvimento-sustentavelinstitui-o-cadastro-municipal-de-atividades-potencialmente-degradadoras-e-utilizadoras-de-recursosnaturais-cmapd-e-a-taxa-de-controle-e-fiscalizacao-ambiental-tcfa-no-municipio-de-salvador-e-da-outrasprovidencias (consulta: 20/02/2020).

\section{Fontes eletrônicas}

INSTITUTO BRASILEIRO DE GEOGRAFIA E ESTATÍSTICA (IBGE) (2002) (2009) (2017). Pesquisa de Informações Básicas (MUNIC) Rio de Janeiro. [acesso a diversas edições e dados] https://www.ibge.gov.br/estatisticas/sociais/habitacao/10586-pesquisa-de-informacoes-basicasmunicipais.html?edicao=10719\&t=sobre/ (consulta: 20/02/2020).

INSTITUTO DE PESQUISA APLICADA (IPEA) (2013) Atlas do Desenvolvimento Humano no Brasil. http://www.atlasbrasil.org.br/2013/ (consulta: 20/02/2020). 


\section{SÃOPAULO15 17. LISBOA $25 \sim 26$ JUN 2020}

INSTITUTO DE PESQUISA APLICADA (IPEA) (2019). ODS 11. Cidades e Comunidades sustentáveis. Disponível em: https://www.ipea.gov.br/ods/ods11.html. (consulta: 01/08/2020).

MINISTÉRIO DO MEIO AMBIENTE (MMA) [2020?] Agenda Nacional de Qualidade Ambiental Urbana. Brasília. https://www.mma.gov.br/agenda-ambiental-urbana.html (consulta: 20/02/2020).

MINISTÉRIO DO MEIO AMBIENTE. [201?] Municípios: PGI elaborados. Brasila. https://www.mma.gov.br/component/k2/item/945.html?ltemid=887 (consulta: 06/ 08/2020).

PROGRAMA CIDADES SUSTENTÁVEIS. [201?] Cidades Signatárias. [s.I.] https://www.cidadessustentaveis.org.br/institucional/pagina/cidades-signatarias. (consulta: 30/06/2020). 